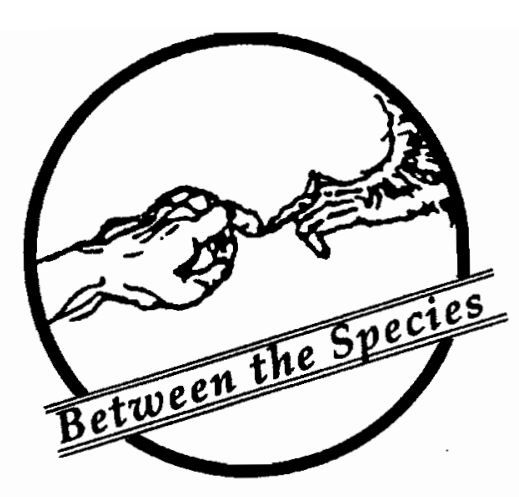

\title{
KOHLBERG AND CONCERN FOR NONHUMANS
}

\author{
Evelyn B. Pluhar \\ Pennsylvania State University \\ Fayette Campus
}

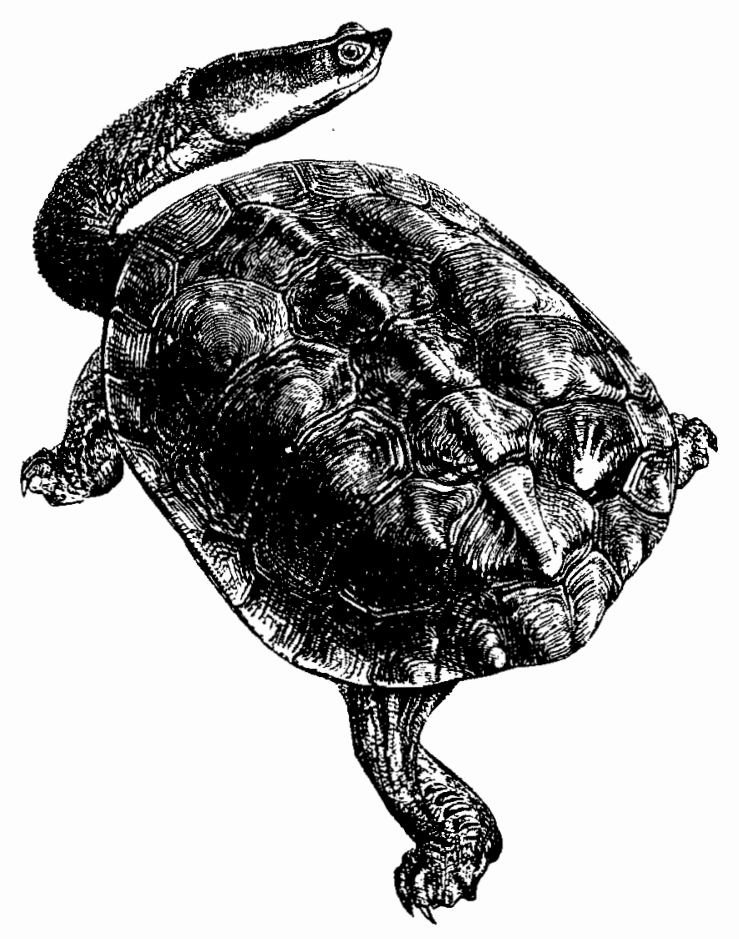

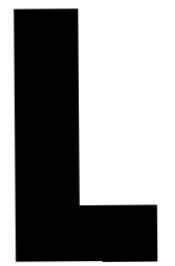

awrence Kohlberg's theory of moral development has been enormously influential in psychology. As Dr. Julie Dunlap states, his work has been concerned exclusively with the development of our moral attitudes toward other humans. Her research is a welcome attempt to use Kohlberg's theory to probe for the development of moral concern about nonhuman animals and nature in general.

We should be aware, however, as Dr. Dunlap is, that some serious doubts about Kohlberg's theory have been raised by psychologists and philosophers. Kohlberg holds that there is a fixed, invariant sequence of stages through which humans progress as their moral thinking

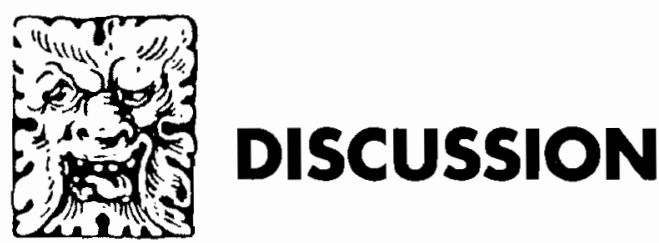


becomes increasingly adequate. These stages are subdivisions of three levels: (I) preconventional or egocentric (Stages 1 and 2), (II) conventional (Stages 3 and 4), and (III) post-conventional (Stages 5 and 6). ${ }^{1}$ There is ample evidence for the existence of these three levels. We can see them in our own histories and in many around us. There are those who require threats of punishment or promises of rewards to abide by moral rules; those who accept such rules without question, happy to follow authority and majority opinion; and those who are capable of autonomous thinking about morality. In this respect, our intuitions seem to match carefully gathered psychological data. Nevertheless, a number of problems have surfaced. Even Kohlberg's own research began to reveal serious flaws in his scheme. To mention just one serious problem, male subjects who were scored at Stage 5 or 4 in high school went off to college and, contrary to the theory, apparently regressed to egocentric relativism (Stage 2) . ${ }^{2}$ Even more troubling to many was the fact that female subjects tested by the Kohlberg dilemmas tended to be rated as less morally developed than many of their male counterparts. As Dr. Dunlap notes, Carol Gilligan has argued extensively that these results reveal the Kohlberg theory to be biased against females and excessively narrow in its exclusive focus on justice concerns in moral thinking. ${ }^{3}$

In response to his problematical data, Kohlberg considered but eventually rejected allowing for moral regression in his theory. He decided instead to revise his scoring manual. Boys formerly classified as having reached the post-conventional level were retroactively classified as conventional. Their "Stage 2" egocentrism was construed as a transitional phase between Stages 4 and 5.4 Moreover, in response to Carol Gilligan's criticisms, Kohlberg changed his classification of male "law and order," Archie Bunker-type responses from Stage 4 to Stage 3, thus further lowering overall male scores. As a result of the scoring manual revisions, the evidence of significant regression disappeared, as well as the comparatively poor showing of women. ${ }^{5}$ Kohlberg now believes that Stage 5 will only be attained by a minority of adult humans. ${ }^{6}$
All his former Stage 6 scores disappeared with the revision, leaving Kohlberg to speculate that only a very few extraordinary individuals (e.g., Socrates, Christ, Gandhi, and King) are fully autonomous moral thinkers. ${ }^{7}$

However, the fact remains that Kohlberg's formerly high-scoring high school boys, reclassified as conventional, did appear to give autonomous, principled responses to the dilemmas. Kohlberg resolved this discrepancy by making two new theoretical postulations: a conventional substage A and a substage $B$ which he characterizes as "the autonomous substage of conventional thinking." 8 Thus, the boys' responses are now scored as being both conventional and autonomous, and the anomalies in the data have magically disappeared. ${ }^{9}$

One cannot help feeling uneasy about this way of dealing with a theoretical crisis. Consider Kohlberg's own description of his decision to recategorize his data:

Because it was unsatisfactory to include regression or retrogression in a moral stage scheme, we were led to (a) revise definitions of Stage 5 (and 6) and (b) to make a distinction between a more morally autonomous B substage and a less autonomous A substage at the conventional level. 10

The ad hoc air of this maneuver is hardly dispelled by Kohlberg's name for it: "our circular boot-strapping approach."11

However, even if one has serious reservations about Kohlberg's classification scheme, it can still be used to show whether adolescents who are engaged in moral reasoning think about animals or the environment in general in the same way in which they think about humans. If we use the scheme, eyes wide open to its limitations, we should be able to find out something.

It's interesting that Kohlberg himself asks questions about animals in his follow-up interviews for the "Heinz" and "Doctor" dilemmas. The following optional questions appears in the Heinz interview: "Suppose it is a pet animal he loves. Should Heinz steal to save the pet animal?"12 In the Doctor interview the animalrelated question is not optional: "When a pet 
animal is badly wounded and will die, it is killed to put it out of its pain. Does the same thing apply here?"13 One has a strong suspicion that Kohlberg's intent here is to classify answers that distinguish between animal and human cases as higher-level than those which do not. Elsewhere Kohlberg gives us the following example of Stage 1 moral thinking: "At the age of four my son joined the pacifist and vegetarian movement and refused to eat meat because, he said, it is bad to kill animals." 14 According to Kohlberg, he and his wife were forced to pose and try to answer this question: "Why is it all right to kill and eat animals but not humans?" For six months all their arguments about "justified" as opposed to "unjustified" killing fell on unresponsive Stage 1 ears. ${ }^{15}$

By contrast, Dr. Dunlap's research exhibits no such preconceptions. She has constructed dilemmas and follow-up questions which allow her to compare adolescents' responses to parallel human and animal moral quandaries in a systematic way. Her data do indeed indicate that boys are capable of showing moral concern about animals and the environment in general, contrary to Nash's speculation that such concern could only arise after Stage 6 has been achieved (making any such individuals scarcer than hen's teeth on Kohlberg's current scoring system). While this is encouraging news to those of us who share these concerns, however, there are grounds for caution in our interpretation of the data.

First, although Dr. Dunlap repeatedly states that the boys she tested used the same "moral logic" to address the animal and human dilemmas, the moral stage scores for the animal dilemmas are consistently lower than stage scores for the parallel human cases.

Although the overlap indicates that some boys did reason at the same stage for humans and animals, a good many apparently did not. (We all know such people. An extremely intelligent, caring physician recently told me quite seriously that it was ridiculous to try to "save the whales." He explained that they were no longer "good for anything" since we have stopped needing oil lamps and corsets.)

Second, even if the boy does reason at the same stage for animals as for humans, this does not necessarily mean that he regards them as being on a moral par. For example, Kohlberg reports the following response from a ten-yearold boy to one of his animal related questions (i.e., should the doctor put the woman out of her misery as one would a badly wounded pet?):

But the husband wouldn't want it, it's not like an animal. If a pet dies you can get along without it - it isn't something you really need. Well, you can get a new wife, but it's not really the same. ${ }^{16}$

The boy is consistently reasoning at Stage 2 here in seeing pet and wife in terms of their instrumental value to the husband, but the animal is clearly downgraded in comparison to the wife.

Nevertheless, Dr. Dunlap's data clearly do demonstrate genuine concern for animals among some boys at Stages 3 and 4. She was also able to elicit some more general pro-environment sentiments. However, despite the title of her paper, the dilemmas she has devised are really more suitable as tests of adolescents' attitudes toward individual animals than their attitudes toward the environment as such. All six of her animal dilemmas are concerned with individual animals, and four of the six concern domestic animals. Environmental ethics, when it is concerned with animals at all, focuses on wild animals; undoubtedly, this is the reason for Dr. Dunlap's wild chimpanzee dilemmas. But environmental ethics encompasses much more as well: concern for nonsentient living beings, for ecological systems, even for (according to some environmental ethicists) the nonliving parts of nature. Perhaps some additional dilemmas could be constructed to test for these concerns. For example, "Should Heinz sabotage logging equipment in order to save a redwood?" "Should Senator Gallo fight or support her constituents' desire to turn a wilderness area into a shopping mall?" Although the Kohlberg scheme was designed to test for moral reasoning about sentient individuals, perhaps it could be extended in such a way to encompass more environmental ethical concerns. 
Many of Dr. Dunlap's subjects did express one concern which environmental ethicists share the desire for preserving members of rare species. I fear, however, that much of that concern arose from the belief that rare animals, unlike "common" animals, are simply less replaceable. This contempt for "common," allegedly "replaceable" animals can generate concern for endangered species, but it has very unfavorable implications for many individual animals. Those who believe that individual sentient animals are morally considerable cannot take heart in such an attitude, although many environmental ethicists can.

The good news in all this for those who are concerned about nonhumans is that many adolescents can and do show empathetic, caring responses for those who don't belong to their own species. Some - those who are able to criticize human society and who suggest that we have behaved irresponsibly toward animals and the environment in general - are even capable of autonomous thinking. This is especially encouraging, since those who are capable of questioning societal norms and behavior are capable of perceiving and rejecting prejudices such as homocentrism and speciesism. Whether we classify these young people's responses as Stage 5 or 6 , or as "substage $\mathrm{B}$," is really not all that important. At least, as Dr. Dunlap has shown, concern for nonhumans is not restricted to a tiny, possibly mythical elite of sages even more advanced than Socrates.

\section{$\underline{\text { Notes }}$}

${ }^{1}$ Lawrence Kohlberg, "Moral Stages and Moralization,"The Psychology of Moral Development (San Francisco: Harper \& Row, 1984), p. 172.

${ }^{2}$ Lawrence Kohlberg, "The Meaning and Measurement of Moral Development," and (with Ann Higgins) "Continuities and Discontinuities in Childhood and in Adult Development Revisited - Again," p. 427, in The Psychology of Moral Development, op. cit.

${ }^{3}$ Carol Gilligan, In a Different Voice (Cambridge, Mass.: Harvard U. Press, 1982). Several philosophers are supportive of Gilligan. See, e.g., Owen Flanagan, "Virtue, Sex, and
Gender: Some Philosophical Reflections on the Moral Psychology Debate," Ethics (92) (April 1982), pp. 499-512; Owen Flanagan and Kathryn Jackson, "Justice, Care and Gender: The Kohlberg-Gilligan Debate Revisited," Ethics 97 (April 1987), pp. 622-637; and Lawrence Blum, "Gilligan and Kohlberg: Implications for Moral Theory," Ethics (98) (April, 1988), pp. 472-491. See also Women and Moral Theory, edited by Eva F. Kittay and Diana T. Meyers (Totowa, N.J.: Rowman \& Littlefield, 1987).

${ }^{4}$ Lawrence Kohlberg, "Continuities and Discontinuities in Childhood and in Adult Development Revisited - Again," with Ann Higgins, op cit.

${ }^{5}$ Lawrence Kohlberg, with Charles Levine and Alexandra Hewer, "Synopses and Detailed Replies to Critics," The Psychology of Moral Development, op. cit., especially p. 343. Nevertheless, the charge that Kohlberg has emphasized the justice orientation at the expense of a caring orientation remains. If women really do tend to employ a care orientation more often than their male counterparts, Kohlberg's theory remains an inadequate description of their development, even if their justice scores are no longer significantly lower than males.

${ }^{6}$ Lawrence Kohlberg, "Moral Stages and Moralization," op. cit., p. 172.

${ }^{7}$ Lawrence Kohlberg, with Charles Levine and Alexandra Hewer, "The Current Formulation of the Theory," The Psychology of Moral Development, op. cit., pp. 270-274.

${ }^{8}$ Lawrence Kohlberg, "Continuities and Discontinuities," op. cit., p. 451.

${ }^{9}$ Kohlberg does, however, admit that one of his cases must be interpreted as having regressed somewhat even on the new scoring system. See his discussion of "Case 65" in "Continuities and Discontinuities," pp. 472-478. Case 65 went from $4-1 / 2$ in college to $4(3)$, then to 4 , and finally to $4 / 5$. The anomalies have virtually all disappeared, however.

${ }^{10}$ Lawrence Kohlberg, "Continuities and Discontinuities," op. cit., p. 428. 
${ }^{11}$ Ibid., note on p. 451. For criticism of other aspects of Kohlberg's theory, see T.M. Reed, "Developmental Moral Theory," Ethics 97 (January, 1987), pp. 441-456.

${ }^{12}$ Lawrence Kohlberg, The Psychology of Moral Development, op. cit., p. 641.

${ }^{13}$ Ibid., p. 645.

${ }^{14}$ Lawrence Kohlberg, "Indoctrination Versus Relativity in Value Education," The Philosophy of Moral Development, op. cit., p. 14.

${ }^{15}$ Ibid., p. 645.

${ }^{16}$ Lawrence Kohlberg, "From 'Is' to 'Ought': How to Commit the Naturalistic Fallacy and Get Away with It in the Study of Moral Development," The Philosophy of Moral Development, op. cit., p. 118.

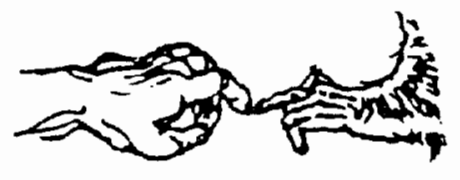

The following prose-poem is written in memory of Paulette Nenner. Paulette was an artist and an animal rights activist. Though neither of us had ever met Dian Fossey, we shared a longstanding admiration for the woman and her work that began for both of us when we first saw those early National Geographic films of Dian interacting with free gorillas, especially with her beloved Digit. Paulette said that someday she wanted to go to Rwanda and help patrol the mountains for poachers. She never made it. She died of pneumonia in March, 1988 in New York City. But I like to think she did at last get to meet her heroine, the woman on the mountain.

- Paulette Callen Nutley, New Jersey

\section{$\underline{\text { A Gorilla In The Mist }}$}

A gorilla stands waiting in the mist. $\mathrm{He}$ is content to wait a long time.

His name...unassuming-from a damaged finger; a shy and gentle being who died with great courage, alone, amid savagery, fighting for his family; and for him, the woman on the mountain grieved and caused a thoughtless world to take note and mark his passing.

She too died, in a way, alone, fighting for her family, amid savagery.

The Cree say that when a human being dies, the soul must stand within a circle of animals - all those one has abused, or killed without need and without respect-in the misty land of the dead, and woe be unto that soul!

It is also said by those who have died and come back that there is, after death, a moving toward a great light, and that along the way one encounters helpers who comfort and encourage us on this journey.

The woman on the mountain...when her turn came...there would have been no circle of animal judges to try her.

She moves toward the light. And out of the mists there steps one to meet her. The one she called Digit. 